\title{
Five-factor personality model versus affective temperaments: a study in a nonclinical Polish sample
}

\author{
Włodzimierz Oniszczenko ${ }^{1 \cdot A, B, C, D, E, F, G}$, Ewa Stanisławiak $k^{2 \cdot B, D, E, F}$ \\ 1: Faculty of Psychology, University of Warsaw, Poland \\ 2: Faculty of Psychology, University of Finance and Management, Warsaw, Poland
}

BACKGROUND

The study aimed to evaluate the relationship between five-factor personality model traits and affective temperaments.

\section{PARTICIPANTS AND PROCEDURE}

The sample consisted of 615 healthy Caucasian adults (395 women and 220 men) recruited from a nonclinical population. Participants' ages ranged from 17 to 69 $(M=30.79, S D=9.69)$. The Polish version of Akiskal's Temperament Evaluation of Memphis, Pisa, Paris and San Diego Auto-Questionnaire was used for the assessment of affective temperaments. The five-factor personality model traits were measured with the Polish version of Costa and McCrae's NEO-FFI Personality Inventory.

\section{RESULTS}

Neuroticism positively correlated with depressive, cyclothymic, irritable and anxious temperaments, but negatively with hyperthymic temperament. Extraversion positively correlated with hyperthymic temperament, but negatively with all other affective temperaments. Neuroticism together with introversion was the best predictor of depressive temperament, accounting for $55 \%$ of the variance. Neuroticism also explained $37 \%$ of the anxious temperament variance and $22 \%$ of cyclothymic temperament variance. Extraversion predicts hyperthymic temperament (accounting for $25 \%$ of the variance) and low agreeableness predicts irritable temperament ( $10 \%$ of explained variance). The results confirmed that women are more depressive, cyclothymic and anxious and less hyperthymic than men and have a higher level of neuroticism than men.

\section{CONCLUSIONS}

The results highlight the importance of two personality traits: neuroticism and extraversion. They may share similarities with certain affective temperaments and may also contribute to development of affective disorders.

KEY WORDS

Big Five; temperaments; healthy adults

CORReSPONDIng AUthor - Prof. Włodzimierz Oniszczenko, Faculty of Psychology, University of Warsaw, 5-7 Stawki Str., 00-183 Warsaw, Poland, e-mail: wlodek@psych.uw.edu.pl

AUthors' CONTRibution - A: Study design - B: Data collection - C: Statistical analysis · D: Data interpretation .

E: Manuscript preparation · F: Literature search · G: Funds collection

TO CITE THIS ARTICLE - Oniszczenko, W., \& Stanisławiak, E. (2019). Five-factor personality model versus affective

temperaments: a study in a nonclinical Polish sample. Current Issues in Personality Psychology, 7(1), 15-23.

RECEIVED 06.03.2018 · REVIEWED 02.01.2019 · ACCEPTED 05.01.2019 • PUBLISHED 04.02.2019 


\section{BACKGROUND}

The main goal of the study was to investigate and evaluate the relationship between personality traits postulated by the Costa and McCrae five-factor personality model (FFM; McCrae \& John, 1992) and Akiskal's (Akiskal \& Akiskal, 2005) affective temperaments as measured by the Temperament Evaluation of Memphis, Pisa, Paris and San Diego Auto-Questionnaire (TEMPS-A) in a nonclinical population.

Affective temperament types (depressive, cyclothymic, hyperthymic, irritable and anxious) are trait-related manifestations that play definitive roles in determining predispositions to affective disorders (Akiskal \& Akiskal, 2005; Pompili et al., 2018; Solmi et al., 2016). Vázquez and Gonda (2013) emphasize that the model of affective temperaments was based on the observation of patients with mood disorders and their healthy first-degree relatives. As has been demonstrated, affective temperaments exhibit good long-term stability and may be considered stable traits (Kawamura et al., 2010). Furthermore, they encompass healthy personality traits (Rovai et al., 2013) and, as demonstrated by data from large national studies employing general and healthy samples, have universal (Vázquez \& Gonda, 2013) and culturally specific characteristics (Vázquez, Tondo, Mazzarini, \& Gonda, 2012).

Costa and McCrae's (McCrae \& John, 1992) fivefactor personality model was developed in order to describe healthy human functioning. The model comprises five broad trait dimensions: neuroticism (or emotional instability), extraversion versus introversion, openness (or unconventionality), agreeableness versus antagonism, and conscientiousness/constraint (Bagby \& Widiger, 2018). Multiple studies (e.g., Kotov, Gamez, Schmidt, \& Watson, 2010; Malouff, Thorsteinsson, \& Schutte, 2005) support a link between FFM traits and psychopathology. Neuroticism seems to be the FFM dimension most closely associated with affective temperaments. Blöink, Brieger, Akiskal and Marneros (2005) demonstrated positive correlations between neuroticism as measured by the NEO FiveFactor Inventory and all the affective temperaments, except for hyperthymic in the German nonclinical sample. Notably, extraversion was negatively correlated with all affective temperaments, again with the exception of hyperthymic (positive correlation) in the German sample. Also, negative correlations between agreeableness and cyclothymic and irritable temperaments were found in this group as well as a positive correlation between conscientiousness and depressive temperament and a negative correlation between conscientiousness and cyclothymic temperament (Blöink et al., 2005). Kwapil et al. (2013) showed that fivefactor personality model traits accounted for between $38 \%$ (irritable temperament) and 49\% (hyperthymic temperament) of total variance in the affective temperaments. Oniszczenko, Stanisławiak, Dembińska-
Krajewska and Rybakowski (2017) demonstrated that neuroticism-related temperament traits, such as emotional reactivity (ER) and perseveration (PE), accounted for $24 \%$ of the anxious temperament variance, while extraversion-related temperament traits such as activity were the best predictors of hyperthymic temperament, accounting for $25 \%$ of the variance. These results also support the hypothesis regarding the relationship between FFM dimensions and affective temperaments.

According to McCrae and Costa (2005), FFM personality traits are endogenous basic tendencies that have been developing since childhood. It is important to note that Costa and McCrae (2001) gave all the traits the status of temperament traits. However, these traits are all commonly referred to as personality traits. Basic tendencies, genetically determined, in interaction with external influences cause characteristic adaptations and behaviors (McCrae \& Sutin, 2018). FFM traits may also contribute to psychopathology symptoms, course and treatment. Of particular importance is the high level of neuroticism and the low levels of extraversion, conscientiousness and agreeableness (Malouff et al., 2005). Affective temperaments are thought to be present in up to $20 \%$ of the healthy general population (Vázquez et al., 2012), while all adults and children since early and middle childhood can be characterized by FFM traits (McCrae \& Costa, 2005). Taking into account that FFM traits are present and can be measured starting from childhood (Caspi, Roberts, \& Shiner, 2005), we assume that FFM traits may serve as factors conducive to development of affective temperaments throughout the lifespan and indirectly contribute to the development of psychopathology.

This study is the first attempt to demonstrate the relationship between the FFM dimensions and affective temperament in a nonclinical Polish sample. We hypothesized that: (a) neuroticism would be positively correlated with depressive, cyclothymic, irritable and anxious temperaments while negatively related to hyperthymic temperament; (b) extraversion would be positively correlated with hyperthymic temperament and negatively with depressive, cyclothymic, irritable and anxious temperaments; (c) agreeableness and conscientiousness would have a negative relationship with affective temperaments.

\section{PARTICIPANTS AND PROCEDURE}

\section{PARTICIPANTS}

The sample consisted of 615 healthy Caucasian adults (395 women and 220 men) recruited from a nonclinical population. Participants' ages ranged from 17 to $69(M=30.79, S D=9.69)$. In terms of education levels, 390 participants had received higher education, 195 participants secondary education and 19 participants pri- 
mary education (11 participants did not any provide information about their education). All self-report questionnaires were administered in a standard manner.

The study was anonymous, and participation was voluntary. Informed consent was obtained from all participants before they were included in the study, and the participants did not receive any compensation. The research project was accepted by the local Research Ethics Commission at the Faculty of Psychology, University of Warsaw.

\section{MEASURES}

The Polish version of the TEMPS-A scale was used for the assessment of affective temperament (Borkowska et al., 2010). TEMPS-A is a self-report instrument comprising 110 items (109 for men) with a yes-no response format (Akiskal, Akiskal, Haykal, Manning, \& Connor, 2005; Dembińska-Krajewska \& Rybakowski, 2014). TEMPS-A is composed of five scales (Cronbach alphas for the Polish version are given in parentheses): depressive $(\alpha=.70)$, cyclothymic $(\alpha=.77)$, hyperthymic $(\alpha=.75)$, irritable $(\alpha=.76)$ and anxious $(\alpha=.83)$. For each answer, a 'yes' response was scored as 1 , and a 'no' response as 0 . These scores were added and divided by the number of items belonging to each affective temperament scale (21 for each of the first four categories of temperaments and 26 for the last category, i.e. anxious temperament).

The five-factor personality model traits were measured with the Polish version of Costa and McCrae's
NEO-FFI Personality Inventory (Zawadzki, Strelau, Szczepaniak, \& Śliwińska, 1998). This questionnaire has 60 items, all with a 5-point Likert response scale, and 12 items per scale. The NEO-FFI consists of the following scales (Cronbach alphas are given in parentheses): neuroticism ( $\mathrm{N} ; \alpha=.80)$, extraversion ( $\mathrm{E} ; \alpha=.77)$, openness to experience $(\mathrm{O} ; \alpha=.68)$, agreeableness $(\mathrm{A} ; \alpha=.68)$, and conscientiousness $(\mathrm{C} ; \alpha=.82)$.

\section{STATISTICAL ANALYSIS}

Statistical analysis was performed using IBM SPSS Statistics 24 (IBM Corp., 2016). The values for skewness and kurtosis in the studied sample were acceptable in order to prove normal distribution. According to Tabachnick and Fidell (2013) the acceptable range for skewness or kurtosis is below +1.5 and above -1.5 . The $t$-test for independent samples was used to test the significance of differences between females and males. Relationships among variables were examined with Pearson's product-moment correlation coefficient. Multiple linear regression analysis was used to estimate whether FFM traits could serve as predictors of affective temperaments.

\section{RESULTS}

Table 1 shows the means and standard deviations as well as skewness and kurtosis values for affective temperaments and FFM traits for the whole sample.

Table 1

Descriptive statistics for the Temperament Evaluation of Memphis, Pisa, Paris and San Diego Auto-Questionnaire and NEO Five-Factor Inventory Scales

\begin{tabular}{lcccc}
\hline Temperament scale & Range observed & $M(S D)$ & Skewness & Kurtosis \\
\hline TEMPS-A & & & & 0.79 \\
Depressive & $0.00-0.95$ & $.34(.16)$ & 0.79 & -0.59 \\
Cyclothymic & $0.00-0.95$ & $.33(.21)$ & 0.51 & -0.61 \\
Hyperthymic & $0.00-1.00$ & $.50(.20)$ & -0.15 & 1.03 \\
Irritable & $0.00-0.95$ & $.21(.18)$ & 1.05 & 0.02 \\
Anxious & $0.00-1.00$ & $.28(.20)$ & 0.77 & -.26 \\
NEO-FFI & & & & -.18 \\
Neuroticism & $0-47$ & $19.75(8.92)$ & .18 & -.13 \\
Extraversion & $8-48$ & $28.63(7.16)$ & -.26 & .00 \\
Openness to & $12-46$ & $27.73(6.18)$ & .40 & .15 \\
experience & $9-45$ & $30.72(6.00)$ & -.24 & -.51 \\
Agreeableness & $7-48$ & $32.96(7.42)$ & & \\
Conscientiousness & & & & \\
\hline
\end{tabular}


Table 2 presents the correlations among age, FFM traits and affective temperaments in the whole sample. A positive correlation was found for age and A and $\mathrm{C}$. Negative correlations was found for age and $\mathrm{N}$ and $\mathrm{O}$ as well as for age and cyclothymic and irritable temperaments. $\mathrm{N}$ positively correlated with depressive, cyclothymic, irritable and anxious temperaments, but negatively with hyperthymic temperament. E negatively correlated with depressive, cyclothymic, irritable and anxious temperaments, but positively correlated with hyperthymic temperament. O negatively correlated with depressive temperament, but positively with cyclothymic and hyperthymic temperaments. Factor A negatively correlated with cyclothymic, irritable and anxious tem- peraments. C negatively correlated with depressive, cyclothymic, irritable and anxious temperaments, but positively with hyperthymic temperament.

Descriptive data about females and males are presented in Table 3 along with differences between the studied groups.

As shown in Table 3, females had higher levels of depressive, cyclothymic and anxious temperaments than males. Males had a higher level of hyperthymic temperament than females. No significant differences were found between the two groups with regard to irritable temperament. Females also showed higher levels of $\mathrm{N}$ and A compared to males. No significant differences were found between the two groups with regard to $\mathrm{E}, \mathrm{O}$ and $\mathrm{C}$.

Table 2

Pearson's r correlations between age, NEO Five-Factor Inventory and Temperament Evaluation of Memphis, Pisa, Paris and San Diego Auto-Questionnaire Scales

\begin{tabular}{lcccccc}
\hline Variable & Age & $\begin{array}{r}\text { TEMPS-A: } \\
\text { Depressive }\end{array}$ & $\begin{array}{c}\text { TEMPS-A: } \\
\text { Cyclothymic }\end{array}$ & $\begin{array}{c}\text { TEMPS-A: } \\
\text { Hyperthymic }\end{array}$ & $\begin{array}{c}\text { TEMPS- A: } \\
\text { Irritable }\end{array}$ & $\begin{array}{c}\text { TEMPS-A: } \\
\text { Anxious }\end{array}$ \\
\hline Age & & .02 & $-.22^{* * *}$ & .04 & $-.16^{* * *}$ & -.01 \\
$\mathrm{~N}$ & $-.13^{* * *}$ & $.58^{* * *}$ & $.58^{* * *}$ & $-.44^{* * *}$ & $.32^{* * *}$ & $.68^{* * *}$ \\
$\mathrm{E}$ & .01 & $-.47^{* * *}$ & $-.18^{* * *}$ & $.66^{* * *}$ & $-.16^{* * *}$ & $-.30^{* * *}$ \\
$\mathrm{O}$ & $-.12^{* *}$ & $-.16^{* * *}$ & $.09^{*}$ & $.17^{* * *}$ & .00 & -.08 \\
$\mathrm{~A}$ & $.15^{* * *}$ & .01 & $-.29^{* * *}$ & -.05 & $-.37^{* * *}$ & $-.14^{* * *}$ \\
$\mathrm{C}$ & $.25^{* * *}$ & $-.14^{* * *}$ & $-.38^{* * *}$ & $.33^{* * *}$ & $-.27^{* * *}$ & $-.20^{* * *}$ \\
\hline
\end{tabular}

Note. ${ }^{*} p<.05,{ }^{* *} p<.01,{ }^{* * *} p<.001 . \mathrm{N}-$ Neuroticism, E - Extraversion, O - Openness to experience, A - Agreeableness, C - Conscientiousness.

Table 3

Gender differences in affective temperaments and five-factor personality model traits $(n=613)$

\begin{tabular}{|c|c|c|c|c|}
\hline Temperament scale & $\begin{array}{c}\text { Females }(n=395) \\
\qquad M(S D)\end{array}$ & $\begin{array}{c}\text { Males }(n=220) \\
M(S D)\end{array}$ & $t$ & Cohen's $d$ \\
\hline \multicolumn{5}{|l|}{ TEMPS-A } \\
\hline Depressive & $.37(.16)$ & $.31(.15)$ & $4.47^{* * *}$ & .39 \\
\hline Cyclothymic & $.34(.21)$ & $.30(.21)$ & $2.24^{*}$ & .19 \\
\hline Hyperthymic & $.48(.20)$ & $.53(.20)$ & $-3.03^{* *}$ & -.25 \\
\hline Irritable & $.21(.17)$ & $.21(.19)$ & -0.57 & .00 \\
\hline Anxious & $.32(.21)$ & $.20(.16)$ & $7.41^{* * *}$ & .64 \\
\hline \multicolumn{5}{|l|}{ NEO-FFI } \\
\hline $\mathrm{N}$ & $21.39(8.81)$ & $16.82(8.36)$ & $6.28^{* * *}$ & .53 \\
\hline E & $28.99(7.13)$ & $28.00(7.18)$ & 1.65 & .14 \\
\hline $\mathrm{O}$ & $27.80(6.08)$ & $27.59(6.36)$ & 0.41 & .03 \\
\hline A & $31.62(6.09)$ & $29.10(5.49)$ & $5.09^{* * *}$ & .40 \\
\hline $\mathrm{C}$ & $33.31(7.43)$ & $32.32(7.38)$ & 1.58 & .13 \\
\hline
\end{tabular}

Note. ${ }^{*} p<.05,{ }^{* *} p<.01,{ }^{* * *} p<.001 . \mathrm{N}-$ Neuroticism, E - Extraversion, O - Openness to experience, A - Agreeableness, C - Conscientiousness. 
To determine the extent to which FFM traits can be considered as predictors of affective temperaments, a multiple linear regression analysis was conducted. Each TEMPS-A scale was treated as a dependent variable, and the five FFM traits as independent variables in the analysis. The results of regressions analysis are presented in Table 4.
From the regression coefficients, all variables were found to be significant predictors of depressive temperament: $\mathrm{N}(\beta=.53, p<.001), \mathrm{E}(\beta=-.32, p<.001)$, $\mathrm{A}(\beta=.12, p<.001), \mathrm{C}(\beta=.16, p<.001)$ and $\mathrm{O}(\beta=-.08$, $p<.01)$. As the results showed, two variables were the best predictors of depressive temperament $-\mathrm{N}$ and low level of E (introversion). Standardized beta coef-

Table 4

Multiple linear regression analysis of five-factor personality model traits as predictors of affective temperaments as measured by the Temperament Evaluation of Memphis, Pisa, Paris and San Diego Auto-Questionnaire

\begin{tabular}{lllll}
\hline Variable & $B$ & SE $B$ & $\beta$ & $\begin{array}{l}\text { Semi-partial } \\
\text { correlations }\end{array}$ \\
\hline
\end{tabular}

TEMPS-A: Depressive

$\mathrm{N}$

E

$\mathrm{O}$

A

C

.01

$-.01$

$-.00$

.00

.00

TEMPS-A: Cyclothymic

$\begin{array}{lr}\mathrm{N} & .01 \\ \mathrm{E} & .00 \\ \mathrm{O} & .00 \\ \mathrm{~A} & -.01 \\ \mathrm{C} & -.00\end{array}$

TEMPS-A: Hyperthymic

$\begin{array}{lr}\text { N } & -.00 \\ \text { E } & .02 \\ \mathrm{O} & .00 \\ \mathrm{~A} & -.0 \\ \mathrm{C} & .00\end{array}$

$-.00$

.02

.00

$-.01$

.00

TEMPS-A: Irritable

$\begin{array}{lr}\mathrm{N} & .00 \\ \mathrm{E} & .00 \\ \mathrm{O} & .00 \\ \mathrm{~A} & -.01 \\ \mathrm{C} & -.00\end{array}$

TEMPS-A: Anxious

$\begin{array}{lrr}\mathrm{N} & .02 & .00 \\ \mathrm{E} & -.00 & .00 \\ \mathrm{O} & -.00 & .00 \\ \mathrm{~A} & -.00 & .00 \\ \mathrm{C} & .00 & .00\end{array}$

$\begin{array}{cr}.53^{* * *} & .46 \\ -.32^{* * *} & -.28 \\ -.08^{* *} & -.08 \\ .12^{* * *} & .11 \\ .16^{* * *} & .14\end{array}$

.46

$-.28$

.08

11

14

.00

.00

$.54^{* * *}$

.47

$.11^{* *}$

.09

$.12^{* * *}$

.12

$-.22 * * *$

$-.21$

$-.14^{* * *}$

$-.12$

.00

.00

$-.19^{* * *}$

$-.17$

$.57^{* * *}$

.50

$.10^{* * *}$

.09

.00

$-.21^{* * *}$

$-.20$

$.10^{* *}$

.09
.00

.00

.00

.00

.00

.00

.00

.00

.00

.00

$$
.24^{* * *}
$$

.03

.05

$-.33^{* * *}$

$-.32$

$-.11^{\text {** }}$

$-.09$

Note. ${ }^{* *} p<.01,{ }^{* * *} p<.001 . \mathrm{N}-$ Neuroticism, E - Extraversion, $\mathrm{O}$ - Openness to experience, $\mathrm{A}$ - Agreeableness, $\mathrm{C}$ - Conscientiousness. 
ficients showed that the higher the level of $\mathrm{N}$ and the lower the level of $\mathrm{E}$ were, the higher was the depressive temperament level. The sum of the squared semipartial correlations showed that $\mathrm{N}$ and low $\mathrm{E}$ accounted for $55 \%$ of the variance in depressive temperament. We also found that five FFM traits were significant predictors of cyclothymic temperament: $\mathrm{N}(\beta=.54$, $p<.001), \mathrm{E}(\beta=.11, p<.01), \mathrm{O}(\beta=.12, p<.001)$, $\mathrm{A}(\beta=-.22, p<.001)$ and $\mathrm{C}(\beta=-.14, p<.001) . \mathrm{N}$ was the best predictor of cyclothymic temperament. The higher the level of $\mathrm{N}$ was, the higher was the cyclothymic temperament level. $\mathrm{N}$ accounted for $22 \%$ of the variance in cyclothymic temperament. Also five FFM traits were found to be significant predictors of hyperthymic temperament: $\mathrm{N}(\beta=-.19, p<.001)$, $\mathrm{E}(\beta=.57, p<.001), \mathrm{O}(\beta=.10, p<.001), \mathrm{A}(\beta=-.21$, $p<.001)$ and $C(\beta=.10, p<.01)$. The results showed $\mathrm{E}$ as the best predictor of hyperthymic temperament. The higher the level of E was, the higher was the hyperthymic temperament level. E accounted for $25 \%$ of the variance in hyperthymic temperament. Three FFM traits were significant predictors of irritable temperament: $\mathrm{N}(\beta=.24, p<.001), \mathrm{A}(\beta=-.33, p<.001)$ and $C(\beta=-.11, p<.01)$. Low level of $A$ (antagonism) was the best predictor of irritable temperaments. The lower the level of A was, the higher was the irritable temperament level. A accounted for $10 \%$ of the variance in irritable temperament. Two FFM traits were found to be significant predictors of anxious temperament: $\mathrm{N}(\beta=.70, p<.001)$ and $\mathrm{C}(\beta=.12, p<.001)$. The best predictor of anxious temperament was $\mathrm{N}$. The higher the level of $\mathrm{N}$ was, the higher was the anxious temperament level. $\mathrm{N}$ accounted for $37 \%$ of the variance in anxious temperament.

\section{DISCUSSION}

This study aimed to evaluate the relationship between FFM traits and affective temperaments. The results obtained here seem to confirm the theoretical assumption of an overlap between these two concepts of personality.

Correlations between the FFM personality traits and affective temperaments confirmed our expectations. Strong positive correlations $(>.50)$ were observed between $\mathrm{N}$ and depressive, cyclothymic, and anxious temperaments, and a positive, but moderate, correlation (> .30) was observed between $\mathrm{N}$ and irritable temperament. These results are not surprising. Our results supported the assumption that $\mathrm{N}$ is a significant risk factor in human mental health (Ormel et al., 2013; Uliaszek, Al-Dajani, \& Bagby, 2015). As Cassin and von Ranson (2005) suggest, $\mathrm{N}$ is a disposition to experience and express negative affect, which is a fundamental trait of personality. The results we obtained are consistent with those of Blöink et al. (2005), who reported positive correlations between neuroticism as measured by the NEO-FFI and all of the affective temperaments, except hyperthymic.

Congruent with our hypothesis, E was positively correlated with hyperthymic temperament and negatively with depressive, cyclothymic, irritable and anxious temperaments. The same result was found by Blöink et al. (2005). Watson, Stasik, Ellickson-Larew and Stanton (2015) showed that, in general, extraversion is negatively correlated with psychopathology, but some lower-order facets of extraversion may be positively related to psychopathology, including bipolar disorder. In turn, in an earlier analysis Karam et al. (2010) suggested that hyperthymic temperament had a protective effect on most mental disorders, except anxiety or bipolar disorders. Temperament traits postulated in the regulative theory of temperament were genetically correlated with $\mathrm{N}$ (i.e., perseveration and emotional reactivity) and $\mathrm{E}$ factors (i.e., briskness, endurance and activity) were correlated with affective temperaments in the same manner as their FFM counterparts (Oniszczenko et al., 2017).

FFM traits, especially $\mathrm{N}$ and $\mathrm{E}$ as measured by the NEO-FFI, were able to predict affective temperaments to varying degrees. Each temperament was predicted by a special pattern of FFM dimensions, with one or two factors being dominant. $\mathrm{N}$ and low level of $\mathrm{E}$ (introversion) together accounted for $55 \%$ of the variance of depressive temperament. Two other affective temperaments (i.e., cyclothymic and anxious) were predicted by $\mathrm{N}$. This trait explained variance from $22 \%$ in the case of cyclothymic temperament to $37 \%$ in the case of anxious temperament. E accounted for $25 \%$ of the hyperthymic temperament variance, and a low A level (antagonism) explained $10 \%$ of the irritable temperament variance. The results confirmed that a high level of $\mathrm{N}$ is a significant risk factor in affective disorders, but introversion and a low level of A can also play an important role in the pathogenesis of these disorders. As a personality trait, C correlated positively with hyperthymic temperament and negatively with cyclothymic, irritable and anxious temperaments. These results suggest that $\mathrm{C}$ may have a protective effect against mental disorders. For example, Naragon-Gainey and Simms (2017) suggest that conscientiousness and high extraversion reduce the risk conferred by high neuroticism in major depression.

Our results confirmed the previous findings that females seem more likely to develop affective disorders compared to men (Seney \& Sibille, 2014). As we demonstrated (see Table 3), females had higher levels of depressive, cyclothymic and anxious temperaments than males and a higher level of $\mathrm{N}$ compared to males.

In summary, FFM is a theory much broader than the concept of affective temperaments. The FFM traits were hypothesized to play an active regulating role between individuals and the external world during the human lifespan. In contrast, Akiskal's affective 
temperaments concept is more specific and refers to the risk of developing mood disorders. This study revealed significant correlations between FFM traits and affective temperaments. Neuroticism had the strongest positive correlation with depressive, cyclothymic, irritable and anxious temperaments, but extraversion, conscientiousness and agreeableness showed negative correlations with the aforementioned temperaments. As suggested by Gonda et al. (2006, 2009), phenotypic correlations may have a common genetic basis based on the genes of the serotonergic system.

The FFM factors predicted affective temperaments fairly well, and the main effects were exerted by neuroticism and extraversion. These results suggest that neuroticism may contribute to the development of affective temperaments as direct risk factors for the development of affective disorders. Extraversion, conscientiousness and agreeableness seem to play a buffering role in the development of affective temperaments and mood disorders. We believe that neuroticism as an FFM trait describes a so-called normal personality, but its extreme severity may favor the development of intensified affective temperaments in a part of the population and expose it to interaction with environmental factors at the risk of affective disorders. At the same time, a high level of extraversion, conscientiousness and openness to experience may serve as a buffer and promote the development of hyperthymic temperament, which represents the most functional and desirable properties (Rovai et al., 2013). Finally, in the statistical analysis, we identified a negative correlation between $\mathrm{C}$ and depressive and anxious temperaments as well as a negative correlation between $\mathrm{E}$ and cyclothymic temperaments. Subsequently, we obtained positive standardized beta coefficients in the fitted regression model for the same pairs of variables. This result appears to be related to the multicollinearity among the predictors in multiple linear regression (Yoo et al., 2014).

Interpretation of our results must consider several potential limitations of the study. The cross-sectional nature of this research makes it impossible to draw any definite conclusions about the direction of the relationship between FFM traits and affective temperaments. FFM traits may be associated with the risk of development of affective disorders through affective temperaments as mediators of this relationship, but further longitudinal studies are needed to corroborate this hypothesis. In addition, we did not control for the mental health status of participants, and a relative over-representation of women was observed in the studied group.

\section{CONCLUSIONS}

In conclusion, the results highlight the importance of two FFM traits, $\mathrm{N}$ and $\mathrm{E}$, as predictors of affective temperaments. They may share similarities with certain affective temperaments and may also contribute to development of affective disorders.

\section{ACKNOWLEDGEMENTS}

This research was supported by a grant from the University of Warsaw (BST No 1777-01-2016). The authors declare that they have no conflict of interest.

\section{REFERENCES}

Akiskal, K. K., \& Akiskal, H. S. (2005). The theoretical underpinnings of affective temperaments: Implications for evolutionary foundations of bipolar disorder and human nature. Journal of Affective Disorders, 85, 231-239. doi: 10.1016/j.jad.2004.08.002

Akiskal, H. S., Akiskal, K. K., Haykal, R. F., Manning, J. S., \& Connor, P. D. (2005). TEMPS-A: Progress towards validation of a self-rated clinical version of the Temperament Evaluation of the Memphis, Pisa, Paris, and San Diego Autoquestionnaire. Journal of Affective Disorders, 85, 3-16. doi: 10.1016/j.jad.2004.12.001

Bagby, R. M., \& Widiger, T. A. (2018). Five Factor Model personality disorder scales: An introduction to a special section on assessment of maladaptive variants of the five factor model. Psychological Assessment, 30, 1-9. doi: 10.1037/pas0000523

Blöink, R., Brieger, P., Akiskal, H. S., \& Marneros, A. (2005). Factorial structure and internal consistency of the German TEMPS-A scale: Validation against the NEO-FFI questionnaire. Journal of Affective Disorders, 85, 77-83. doi: 10.1016/S01650327(03)00101-0

Borkowska, A., Rybakowski, J. K., Drożdż, W., Bieliński, M., Kosmowska, M., Rajewska-Rager, A., Bucinski, A., Akiskal, K. K., \& Akiskal, H. S. (2010). Polish validation of the TEMPS-A: The profile of affective temperaments in a college student population. Journal of Affective Disorders, 123, 36-41. doi: 10.1016/j.jad.2009.09.024

Caspi, A., Roberts, B. W., \& Shiner, R. L. (2005). Personality Development: Stability and Change. Annual Review of Psychology, 56, 453-484. doi: 10.1146/annurev.psych.55.090902.141913

Cassin, S. E., \& von Ranson, K. M. (2005). Personality and eating disorders: a decade in review. Clinical Psychology Review, 25, 895-916. doi: 10.1016/j. cpr.2005.04.012

Costa Jr., P. T., \& McCrae, R. R. (2001). A theoretical context for adult temperament. In T. D. Wachs \& G. A. Kohnstamm (Eds.), Temperament in context (pp. 1-21). Mahwah, NJ: Erlbaum.

Dembińska-Krajewska, D., \& Rybakowski, J. (2014). The Temperament Evaluation of Memphis, Pisa 
and San Diego Autoquestionnaire (TEMPS-A) - An important tool to study affective temperaments. Psychiatria Polska, 48, 261-276.

Gonda, X., Rihmer, Z., Zsombok, T., Bagdy, G., Akiskal, K. K., \& Akiskal, H. S. (2006). The 5HTTLPR polymorphism of the serotonin transporter gene is associated with affective temperaments as measured by TEMPS-A. Journal of Affective Disorders, 91, 125-131. doi: 10.1016/j.jad.2005.12.048

Gonda, X., Fountoulakis, K. N., Juhasz, G., Rihmer, Z., Lazary, J., Laszik, A., Akiskal, H. S., \& Bagdy, G. (2009). Association of the s allele of the 5-HTTLPR with neuroticism-related traits and temperaments in a psychiatrically healthy population. European Archives of Psychiatry and Clinical Neuroscience, 259, 106-113. doi: 10.1007/s00406-008-0842-7

IBM Corp. (2016). IBM SPSS Statistics for Windows, Version 24.0. Armonk, NY: IBM Corp.

Karam, E. G., Salamoun, M. M., Yeretzian, J. S., Mneimneh, Z. N., Karam, A. N., Fayyad, J., Hantouche, E., Akiskal, K. K., \& Akiskal, H. S. (2010). The role of anxious and hyperthymic temperaments in mental disorders: a national epidemiologic study. World Psychiatry, 9, 103-110. doi: 10.1002/j.2051-5545.2010.tb00287.x

Kawamura, Y., Akiyama, T., Shimada, T., Minato, T., Umekage, T., Noda, Y., Ukawa, K., Hashidume, C., Sakai, Y., Otowa, T., Sasaki, T., \& Akiskal, H. S. (2010). Six-year stability of affective temperaments as measured by TEMPS-A. Psychopathology, 43, 240-247. doi: 10.1159/000313522

Kotov, R., Gamez, W., Schmidt, F., \& Watson, D. (2010). Linking "big" personality traits to anxiety, depressive, and substance use disorders: A metaanalysis. Psychological Bulletin, 136, 768-821. doi: 10.1037/a0020327

Kwapil, T. R., DeGeorge, D., Walsh, M. A., Burgin, C. J., Silvia, P. J., \& Barrantes-Vidal, N. (2013). Affective temperaments: Unique constructs or dimensions of normal personality by another name? Journal of Affective Disorders, 151, 882-890. doi: 10.1016/j. jad.2013.07.028

Malouff, J. M., Thorsteinsson, E. B., \& Schutte, N. S. (2005). The relationship between the Five-Factor Model of personality and symptoms of clinical disorders: A meta-analysis. Journal of Psychopathology and Behavioral Assessment, 27, 101-114. doi: 10.1007/s10862-005-5384-y

McCrae, R. R., \& Costa Jr., P. T. (2005). Personality in adulthood: A Five-Factor Theory perspective $\left(2^{\text {nd }}\right.$ ed.). New York, NY: Guilford Press.

McCrae, R. R., \& Sutin, A. R. (2018). A Five-Factor Theory perspective on causal analysis. European Journal of Personality, 32, 151-166. doi: 10.1002/per.2134

McCrae, R. R., \& John, O. P. (1992). An introduction to the five-factor model and its applications. Journal of Personality, 60, 175-215. doi: 10.1111/j.14676494.1992.tb00970.x
Naragon-Gainey, K., \& Simms, L. J. (2017). Three-way interaction of neuroticism, extraversion, and conscientiousness in the internalizing disorders: Evidence of disorder specificity in a psychiatric sample. Journal of Research in Personality, 70, 16-26. doi: 10.1016/j.jrp.2017.05.003

Oniszczenko, W., Stanisławiak, E., DembińskaKrajewska, D., \& Rybakowski, J. (2017). Regulative Theory of Temperament versus affective temperaments measured by the Temperament Evaluation of Memphis, Pisa, Paris and San Diego AutoQuestionnaire (TEMPS-A): A study in a non-clinical Polish sample. Current Issues in Personality Psychology, 5, 73-82. doi: 10.5114/cipp.2017.65847

Ormel, J., Jeronimus, B. F., Kotov, R., Riese, H., Bos, E. H., Hankin, B., Rosmalen, J. G. M., \& Oldehinkel, A. J. (2013). Neuroticism and Common Mental Disorders: Meaning and utility of a complex relationship. Clinical Psychology Review, 33, 686-697. doi: 10.1016/j.cpr.2013.04.003

Pompili, M., Baldessarini, R. J., Innamorati, M., Vázquez, G. H., Rihmer, Z., Gonda, X., Forte, A., Lamis, D. A., Erbuto, D., Serafini, G., Fiorillo, A., Amore, M., \& Girardi, P. (2018). Temperaments in psychotic and major affective disorders. Journal of Affective Disorders, 225, 195-200. doi: 10.1016/j. jad.2017.08.026

Rovai, L., Maremmani, A. G., Rugani, F., Bacciardi, S., Pacini, M., Dell'Osso, L., Akiskal, H. S., \& Maremmani, I. (2013). Do Akiskal \& Mallya's affective temperaments belong to the domain of pathology or to that of normality? European Review for Medical and Pharmacological Science, 17, 2065-2079.

Seney, M. L., \& Sibille, E. (2014). Sex differences in mood disorders: perspectives from humans and rodent models. Biology of Sex Differences, 5, 17. doi: 10.1186/s13293-014-0017-3

Solmi, M., Zaninotto, L., Toffanin, T., Veronese, N., Lin, K., Stubbs, B., Fornaro, M., \& Correll, C. U. (2016). A comparative meta-analysis of TEMPS scores across mood disorder patients, their firstdegree relatives, healthy controls, and other psychiatric disorders. Journal of Affective Disorders, 196, 32-46. doi: 10.1016/j.jad.2016.02.013

Tabachnick, B. G., \& Fidell, L. S. (2013). Using multivariate statistics ( $6^{\text {th }}$ ed.). Boston, MA: Pearson.

Uliaszek, A. A., Al-Dajani, N., \& Bagby, R. M. (2015). The relationship between psychopathology and a hierarchical model of normal personality traits: Evidence from a psychiatric patient sample. Journal of Personality Disorders, 29, 719-734. doi: 10.1521/pedi_2014_28_170

Vázquez, G. H., \& Gonda, X. (2013). Affective temperaments and mood disorders: A review of current knowledge. Current Psychiatry Reviews, 9, 21-32. doi: 10.2174/1573400511309010004

Vázquez, G. H., Tondo, L., Mazzarini, L., \& Gonda, X. (2012). Affective temperaments in general popu- 
lation: A review and combined analysis from national studies. Journal of Affective Disorders, 139, 18-22. doi: 10.1016/j.jad.2011.06.032

Watson, D., Stasik, S. M., Ellickson-Larew, S., \& Stanton, K. (2015). Extraversion and psychopathology: A facet-level analysis. Journal of Abnormal Psychology, 124, 432-446. doi: 10.1037/abn0000051

Yoo, W., Mayberry, R., Bae, S., Singh, K., Peter He, Q., \& Lillard, J. W. (2014). A study of effects of multicollinearity in the multivariable analysis. International Journal of Applied Science and Technology, 4, 9-19.

Zawadzki, B., Strelau, J., Szczepaniak, P., \& Śliwińska, M. (1998). Inwentarz Osobowości NEO-FFI Costy i McCrae. Adaptacja polska. Podręcznik [Costa and McCrae's NEO-FFI Personality Inventory. Polish adaptation. Manual]. Warszawa: Pracownia Testów Psychologicznych Polskiego Towarzystwa Psychologicznego. 